\title{
Evaluating the Validity of a Food Frequency Questionnaire in Comparison with a 7-Day Dietary Record for Measuring Dietary Intake in a Population of Survivors of Colorectal Cancer
}

Citation for published version (APA):

Koole, J. L., Bours, M. J. L., Breedveld-Peters, J. J. L., van Roekel, E. H., van Dongen, M. C. J. M., Eussen, S. J. P. M., van Zutphen, M., van Duijnhoven, F. J. B., Boshuizen, H. C., \& Weijenberg, M. P. (2020). Evaluating the Validity of a Food Frequency Questionnaire in Comparison with a 7-Day Dietary Record for Measuring Dietary Intake in a Population of Survivors of Colorectal Cancer. Journal of the Academy of Nutrition and Dietetics, 120(2), 245-257. https://doi.org/10.1016/j.jand.2019.09.008

Document status and date:

Published: 01/02/2020

DOI:

10.1016/j.jand.2019.09.008

Document Version:

Publisher's PDF, also known as Version of record

\section{Document license:}

Taverne

\section{Please check the document version of this publication:}

- A submitted manuscript is the version of the article upon submission and before peer-review. There can be important differences between the submitted version and the official published version of record. People interested in the research are advised to contact the author for the final version of the publication, or visit the DOI to the publisher's website.

- The final author version and the galley proof are versions of the publication after peer review.

- The final published version features the final layout of the paper including the volume, issue and page numbers.

Link to publication

\footnotetext{
General rights rights.

- You may freely distribute the URL identifying the publication in the public portal. please follow below link for the End User Agreement:

www.umlib.nl/taverne-license

Take down policy

If you believe that this document breaches copyright please contact us at:

repository@maastrichtuniversity.nl

providing details and we will investigate your claim.
}

Copyright and moral rights for the publications made accessible in the public portal are retained by the authors and/or other copyright owners and it is a condition of accessing publications that users recognise and abide by the legal requirements associated with these

- Users may download and print one copy of any publication from the public portal for the purpose of private study or research.

- You may not further distribute the material or use it for any profit-making activity or commercial gain

If the publication is distributed under the terms of Article 25fa of the Dutch Copyright Act, indicated by the "Taverne" license above, 


\section{Evaluating the Validity of a Food Frequency Questionnaire in Comparison with a 7-Day Dietary Record for Measuring Dietary Intake in a Population of Survivors of Colorectal Cancer}

Janna L. Koole, MSc; Martijn J. L. Bours, PhD; José J. L. Breedveld-Peters, PhD; Eline H. van Roekel, PhD; Martien C. J. M. van Dongen, PhD; Simone J. P. M. Eussen, PhD; Moniek van Zutphen, MSc; Fränzel J. B. van Duijnhoven, PhD; Hendriek C. Boshuizen, PhD; Matty P. Weijenberg, PhD

\author{
ARTICLE INFORMATION \\ Article history: \\ Submitted 29 March 2019 \\ Accepted 5 September 2019 \\ Available online 3 December 2019

\section{Keywords:} \\ Food frequency questionnaire \\ Dietary record \\ Validity \\ Nutrients \\ Colorectal cancer
}

2212-2672/Copyright (C) 2020 by the Academy of Nutrition and Dietetics.

https://doi.org/10.1016/j.jand.2019.09.008

\begin{abstract}
Background Food frequency questionnaires (FFQs) are a commonly used method to assess dietary intake in epidemiological studies. It is important to evaluate the validity of FFQs in the population of interest.

Objective To evaluate the validity of an FFQ for measuring dietary intake in survivors of colorectal cancer (CRC), relative to a 7-day dietary record.

Design Dietary intake was assessed 1 year after the end of CRC treatment. Participants first completed a 7-day dietary record and 2 weeks later a 253-item FFQ that measured intake in the preceding month.
\end{abstract}

Participants/setting Data were used from a subsample of participants $(n=100)$ enrolled in an ongoing prospective study (EnCoRe study) in the Netherlands, from 2015 to 2018.

Main outcome measures Estimated intakes of total energy, 19 nutrients, and 20 food groups as well as scoring adherence to the dietary recommendations of the World Cancer Research Fund/American Institute for Cancer Research (WCRF/AICR) were compared between both dietary assessment methods.

Statistical analyses performed Means and standard deviations, Spearman rank correlations corrected for within-person variation and total energy, and $\kappa$ agreement between quintiles were assessed.

Results The median Spearman correlation corrected for within-person variation for nutrients and total energy was 0.60 . Correlations $>0.50$ were found for 15 of 19 nutrients, with highest agreement for vitamin B-12 (0.74), polysaccharides (0.75), and alcohol (0.91). On average, $73 \%$ (range $=60 \%$ to $84 \%$ ) of participants were classified into the exact same or adjacent nutrient quintile. The median Spearman correlation corrected for within-person variation for food groups was 0.62 . Correlations $>0.50$ were found for 17 of 20 food groups, with highest agreement for cereals and cereal products (0.96), fish (0.96), and potatoes (0.99). The Spearman correlation between total scores of the WCRF/AICR dietary recommendations was 0.53 .

Conclusions Relative to a 7-day dietary record, the validity of an FFQ for measuring dietary intake among survivors of CRC appeared moderate to good for most nutrients and food groups.

J Acad Nutr Diet. 2020;120(2):245-257.

\section{$\mathrm{T}$} HE ASSESSMENT OF DIETARY INTAKE CONTINUES TO be a challenging and complex practice. Food frequency questionnaires (FFQs) are the most commonly used method to measure habitual dietary intake in epidemiological studies because of their time and cost efficiency. ${ }^{1}$ However, like all dietary assessment methods, FFQs are not free from measurement error. The predefined list of foods may not comprise the full variety of foods of a person's diet, and the retrospective nature of such questionnaires may introduce recall bias, leading to an inaccurate estimation of dietary intake. ${ }^{2}$ Moreover, portion sizes are difficult to measure in a standardized way when using a questionnaire. Therefore, FFQs may be considered as a semiquantitative assessment method generally not intended to assess actual intake but rather to rank subjects according to their habitual intake.

It is important to evaluate the validity of FFQs in the population of interest to assess the credibility and legitimacy of 
the acquired dietary intake information. ${ }^{3}$ Dietary records are considered a suitable comparison method for evaluating the validity of FFQs because the random errors in dietary records, mostly caused by intraindividual day-to-day variation, minimally correlate with bias known to occur in FFQs. ${ }^{3,4}$ Dietary records do not rely upon memory and have no limitation to the type or number of recorded food items. Portion sizes are estimated by using standardized methods or by the weighing of foods by participants. ${ }^{5}$ Correlation coefficients in previous agreement studies among healthy subjects comparing FFQs to dietary records mostly ranged between 0.3 and 0.7 for nutrients and food groups. ${ }^{6-8}$

To correctly investigate the relation between diet and disease, accurate assessment of dietary intake is of great importance in nutritional epidemiological studies. ${ }^{5}$ Aspects of the diet have been identified as potential determinants influencing quality of life and prognosis after colorectal cancer (CRC), but evidence is still limited. A balanced diet with high intakes of fruits and vegetables has previously been associated with higher quality-of-life outcomes in a crosssectional study of over 9,000 survivors of cancer, including survivors of CRC. ${ }^{9}$ In addition, the consumption of red meat, processed meat, low-quality carbohydrates, and sugarsweetened beverages may play a role in CRC recurrence and mortality, but more research is needed to tailor dietary and lifestyle recommendations for survivors of CRC. ${ }^{10,11}$ Because specific dietary recommendations for survivors of cancer are lacking, survivors of cancer are currently advised to follow dietary recommendations meant for the prevention of cancer. The 2007 World Cancer Research Fund/American Institute for Cancer Research (WCRF/AICR) lifestyle recommendations have previously been operationalized into a lifestyle score to assess adherence to the recommendations. ${ }^{12-14}$ Lifestyle scores can be useful for evaluating diet and lifestyle quality on a population level, including in survivors of CRC. ${ }^{15,16}$ The current research group previously found that survivors of CRC with higher adherence to lifestyle recommendations reported better physical functioning and less fatigue in crosssectional analyses 2 to 10 years postdiagnosis using dietary records. ${ }^{16}$

This study aimed to evaluate the validity of an FFQ for measuring dietary intake in a population of survivors of CRC, using a 7-day dietary record as the reference method. Both methods were compared with respect to a selection of nutrients, food groups, and scoring on the WCRF/AICR dietary recommendations.

\section{METHODS}

\section{Population and Study Design}

The current study was conducted in a subsample of 100 participants enrolled in the Energy for Life after ColoRectal Cancer (EnCoRe) study. ${ }^{17}$ This multicenter prospective cohort study is ongoing since 2012 and aims to study how lifestyle factors influence quality of life, health status, functioning, and prognosis of survivors of CRC. Patients with stage I, II, or III CRC, including recurrent CRC, are included upon diagnosis in three Dutch hospitals. Patients are excluded in case of stage IV CRC, comorbidities obstructing participation (eg, cognitive disorders), or inability to understand the Dutch language. Extensive data are collected at multiple times from CRC diagnosis until 5 years after the end of initial therapy. Before

\section{RESEARCH SNAPSHOT}

Research Question: What is the validity of a food frequency questionnaire compared with a 7-day dietary record for measuring dietary intake in a population of survivors of colorectal cancer?

Key Findings: Validity was evaluated in 100 survivors of colorectal cancer participating in an ongoing prospective study. Spearman rank correlations corrected for withinperson variation ranged between 0.14 and 0.91 (median $=0.60$ ) for 19 nutrients and total energy and between 0.31 and 0.99 (median=0.62) for 20 food groups.

the start of CRC treatment, a 253-item semiquantitative FFQ is used to assess habitual dietary intake within the year before CRC diagnosis. Subsequently, 7-day dietary records are used to measure intake at follow-up at 6 weeks, 6 months, and 1,2 , and 5 years after CRC treatment.

For the current study, participants were asked to participate during the regular 1-year posttreatment follow-up visit of the EnCoRe study. Every participant who completed a 7day dietary record for this visit was eligible to participate in the current study and was asked to fill out an additional FFQ subsequent to the dietary record. The FFQ was sent out by postal mail after the dietary record had been returned and participants were provided with an envelope to also return the FFQ after completion. The FFQ was completed approximately 2 weeks after completion of the 7-day dietary record.

Participants of the EnCoRe study were recruited for the current study between August 2015 and January 2018. A total of 100 of 170 invited persons were willing to participate in the current study (response rate 59\%) and filled out and returned the FFQ. Approval for the current study was obtained from the Medical Ethics Committee of the University Hospital Maastricht and Maastricht University, the Netherlands, and all participants provided written informed consent.

\section{FFQ}

An adapted version of the EnCoRe FFQ that is being used pretreatment was used for the current study; instead of a reference period of 1 year, participants were asked to report their intake over the preceding month. In this way, the reference period of the FFQ overlapped with the week in which the 7-day dietary record was completed, to allow for a valid comparison of dietary intakes obtained from both methods. Apart from the reference period, the FFQ to be evaluated was identical to the pretreatment FFQ. Participants received extensive verbal instructions on how to fill in the pretreatment FFQ and written instructions were provided again with the FFQ for the current study. To guarantee highquality data, participants were contacted by telephone after completion of the FFQ to clarify incomplete or contradicting answers. The 101 main questions of the FFQ covering 253 unique food products, were subdivided into an overarching question on frequency of consumption and a subquestion on quantity of consumption. The question on frequency of consumption ranged from "not used," "1 day a month," "2 to 3 days a month," to "7 days a week" on a 10-point scale (eg, 
"How often did you eat bread in the past month?"). The question on quantity of consumption ranged from " $<1$ portion a day" to " $>12$ portions a day" on a 14-point scale (eg, "On average, how many slices of bread did you eat on 1 day?"). The answer options for portion or serving size depended on the type of product. Intake frequencies of specific types of foods (eg, types of bread, cheese, red meat, fruits, vegetables, or cooking fats) were included in additional subquestions. Mean nutritional values were calculated based on the 2011 Dutch Food Composition Database, which contains energy and macro- and micronutrient values for food products in the Netherlands. ${ }^{18}$ One FFQ item could represent multiple food codes in the 2011 Dutch Food Composition Database. A weighted average of the nutritional value of food codes of the 2011 Dutch Food Composition Database was constructed for each FFQ item, based on quantity of consumption according to the Dutch National Food Consumption Survey. ${ }^{19}$

\section{Dietary Records}

Participants received detailed verbal instructions by a trained research dietitian on how to fill in the 7-day dietary record during the 1-year follow-up home visit. The dietary records also contained detailed written instructions. Participants started recording their diet on the next day and were instructed to return the record by postal mail when 7 consecutive days were completed. The dietary record was prestructured with a separate page for each mealtime (breakfast, lunch, dinner) and for three snacking moments between meals. It further contained sufficient open space to note product (brand) names, ingredients, amounts in grams or standardized household measures (eg, spoon, glass), recipes, and preparation methods. Participants were encouraged to be as specific as possible and to write down foods and drinks directly after consumption. After completion, records were checked for incomplete or inconsistent information, and, if needed, clarification was requested by telephone by the dietitian who had visited the participant before. Coding of the dietary records was performed by qualified research dietitians, according to Standard Operating Procedures. ${ }^{16}$ In short, the coding of food items was carried out using the 2011 Dutch Food Composition Database. ${ }^{18}$ Coding of the quantity of foods was based on a Dutch dietary table providing information on the weight (in grams) of food products and the weight (in grams) of standard portion sizes, often given for small, medium, or large variations of the food product or portion size. ${ }^{20}$ After coding, data entry was performed by another dietitian who concurrently performed a quality control check on the coding of the record. Web-based food calculation software was used (Compl-eat; Wageningen University \& Research), which allows the export of dietary data both on nutrient and food group level. ${ }^{21}$ Every participant completed all 7 days of the dietary record.

\section{Nutrients and Food Groups}

The FFQs and dietary records were compared for the intake of total energy, 19 nutrients, and 20 food groups. In the comparison, the macronutrients protein, total fat, as well as saturated fat, monounsaturated fatty acids and polyunsaturated fatty acids, carbohydrates, mono- and disaccharides, polysaccharides, and alcohol were included.
Furthermore, a number of nutrients were selected for comparison based on their (potential) relevance in relation to CRC, including dietary fiber, calcium, magnesium, riboflavin, vitamin B-6, vitamin B-12, vitamin D, folate, folic acid, and dietary folate equivalents. For both methods, food groups were constructed based on the existing food groups in the 2011 Dutch Food Composition Database ${ }^{18}$ and included bread; savory bread spreads; cheese; milk and milk products; eggs; cereals and cereal products; soups; potatoes; vegetables; legumes; meat, meat products, and poultry; fish; soy products and vegetarian products; mixed dishes; fats, oils and savory sauces; fruits; sugar, sweets, and sweet sauces; nuts, seeds, and snacks; pastry and cookies; and alcoholic and nonalcoholic beverages. The herbs and spices group was not included because information on the consumption of herbs and spices was not collected through the dietary records.

\section{WCRF/AICR Dietary Recommendations}

The WCRF/AICR recommendations consist of components on body composition, physical activity, and the diet. Level of adherence to the dietary recommendations according to both dietary intake assessment methods was compared for the six dietary components and the total score (ie, the recommendation on the energy density of the diet, sugar-sweetened drink intake, fruit and vegetable intake, dietary fiber intake, red and processed meat intake, and alcohol intake). Our research group previously operationalized the recommendations according to the $2007 \mathrm{WCRF} / \mathrm{AICR}$ guidelines, ${ }^{16}$ and we adapted the operationalization to the updated 2018 guidelines ${ }^{14}$ for the current analyses. The update involved adjusted threshold values for dietary fiber (consumption of at least 30 instead of 25 grams per day) and alcohol (preferably no alcohol instead of $\leq 2$ drinks per day for men and $\leq 1$ drink per day for women). Threshold values for the consumption of sugar sweetened drinks, fruit and vegetables, and red and processed meat did not change. The recommendation on the energy density of the diet was operationalized according to the 2007 recommendations. ${ }^{13}$

\section{Other Variables}

Clinical information on cancer type and stage was obtained from medical records. Body mass index (measured in kilograms per square meter) was calculated from body height and weight, measured by dietitians at the pre-CRC treatment (height measurements) and the 1-year posttreatment home visit (only weight measurement). Height and weight were measured without shoes while using the same portable stadiometer and scale (seca 861; Seca) for each participant.

\section{Statistical Analyses}

Extensive data cleaning was performed on nutrient and food product level for both methods. The original questionnaire or record was checked in case of extreme values to evaluate whether values were correctly entered and were plausible based on reported intake. Extreme yet plausible values were not excluded as the study aimed to evaluate how both methods correlated for the entire range of intake, including the extremes.

Descriptive analyses were performed for the included participants $(n=100)$ and compared with the subset of nonresponders $(\mathrm{n}=70)$ by using independent $t$ tests for continuous 
variables and $\chi^{2}$ tests for categorical variables. Absolute intakes of nutrients and food groups as measured by the FFQ and the 7-day dietary record were compared based on their means and standard deviations. Spearman rank correlations were calculated to assess the agreement in ranking of subjects according to their intake, the main purpose when using FFQs in nutritional epidemiological research. The Spearman correlation coefficients of nutrients and food groups were adjusted for the within-person day-to-day variability that could be measured for the dietary records assessed over 7 days. These corrected coefficients were calculated in SAS (SAS Institute Inc) according to the method as described by Rosner and Glynn. ${ }^{22}$ In addition, energy-adjustment was applied by using the residual method, which was done separately for the FFQ and dietary record. ${ }^{23}$ In line with previous validation studies on dietary assessment methods, ${ }^{5}$ correlations $>0.50$ were considered "moderate to good". ${ }^{24}$ Sex-specific Bland-Altman plots were constructed for total energy and macronutrients.

The proportion of participants classified into the same quintile, the next (adjacent) quintile, and the opposite (extreme) quintile of nutrient intakes based on both methods were compared. Weighted Cohen's $\kappa$ coefficients were calculated, with linearly decreasing weights for cells further from the diagonal of the $5 \times 5$ cross-table (ie, a weight of 1 was given to the five diagonal cells representing exact agreement, weights of $0.75,0.50$, and 0.25 to the eight, six, and four respective cells in between, and a weight of 0 to the 2 extreme cells on maximal distance from the diagonal). $\kappa$ Values (unweighted and weighted) of $>0.40$ can be interpreted as "moderate agreement" and were considered acceptable. ${ }^{24}$ Furthermore, mean energyadjusted nutrient intakes from the dietary records were calculated for quintiles based on the FFQ energy-adjusted intakes. Total scoring on the WCRF/AICR dietary recommendations was compared using Spearman correlation coefficients, and the scoring of $0,0.5$, or 1 point was compared using weighted $\kappa$ coefficients, with weights of 1 , 0.5 , and 0 for the consecutive categories.

All statistical analyses were conducted using IBM SPSS Statistics 24 (IBM Corp), ${ }^{25}$ except for the analyses of the Spearman crude correlations and correlations corrected for within-person variation that were conducted in SAS 9.4. ${ }^{26} P<0.05$ was considered statistically significant.

\section{RESULTS}

\section{Study Population Characteristics}

Participants had a mean age of $65 \pm 8$ years, and $76 \%$ of them were men (Table 1 ). Thirty-seven percent had been diagnosed with stage III CRC, whereas $23 \%$ were diagnosed with stage II CRC, and 35\% with stage I CRC. In comparison with the responders, nonresponders were significantly older (68.1 vs 65.4 years, $P=0.047$ ) and more often women (41\% vs $24 \%, P=0.016$ ). Responders and nonresponders were similar in terms of body mass index, cancer stage,

Table 1. Characteristics of responders and nonresponders of the validation of a food frequency questionnaire among survivors of colorectal cancer, from August 2015 to January 2018, in the southeast of the Netherlands

\begin{tabular}{|c|c|c|c|}
\hline Characteristic & Responders $(n=100)$ & Nonresponders $(n=70)$ & $P$ value $^{a}$ \\
\hline Sex & \multicolumn{3}{|c|}{$\longleftrightarrow n(\%) \longrightarrow$} \\
\hline Men & $76(76.0)$ & $41(58.6)$ & 0.016 \\
\hline Women & $24(24.0)$ & $29(41.4)$ & \\
\hline & \multicolumn{3}{|c|}{$\longleftrightarrow$ mean $\pm S D^{b} \longrightarrow$} \\
\hline Age, y & $65.4 \pm 7.7$ & $68.1 \pm 9.2$ & 0.047 \\
\hline Body mass index & $28.5 \pm 4.6$ & $28.5 \pm 4.5$ & 0.986 \\
\hline Cancer stage $^{d}$ & \multicolumn{3}{|c|}{$\longleftrightarrow n(\%) \longrightarrow$} \\
\hline I & $35(35.0)$ & $20(28.6)$ & 0.529 \\
\hline ॥ & $23(23.0)$ & $16(22.9)$ & \\
\hline III & $37(37.0)$ & $32(45.7)$ & \\
\hline Type of cancer & & & 0.707 \\
\hline Colon & $60(60.0)$ & $44(62.9)$ & \\
\hline \multirow[t]{2}{*}{ Rectum } & $40(40.0)$ & $26(37.1)$ & \\
\hline & \multicolumn{3}{|c|}{$\longleftrightarrow$ mean $\pm S D \longrightarrow$} \\
\hline Total energy intake (kcal/day) & $2,083 \pm 447$ & $1,963 \pm 450$ & 0.089 \\
\hline Men & $2,193 \pm 418$ & $2,110 \pm 407$ & 0.302 \\
\hline Women & $1,733 \pm 352$ & $1,754 \pm 432$ & 0.842 \\
\hline
\end{tabular}

${ }^{a} P$ values were obtained using independent $t$ tests (continuous variables) and $\chi^{2}$ tests (categorical variables).

${ }^{\mathrm{b}} \mathrm{SD}=$ standard deviation.

${ }^{c}$ Calculated as $\mathrm{kg} / \mathrm{m}^{2}$.

${ }^{\mathrm{d} D o e s}$ not add up to $100 \%$ because of missing stages. 
cancer type (colon or rectum), and total energy intake as measured by the dietary record method.

\section{Comparing Absolute Intakes}

Energy intake according to the FFQ and dietary record ranged between 1,276 and 4,367 and between 553 and 5,064 kcal per day, respectively. Mean daily energy intake was on average approximately $100 \mathrm{kcal}$ higher when measured by the FFQ compared with the dietary record (2,178 vs 2,083 kcal, Table 2$)$. According to the dietary record, mean total daily energy intake among men was 2,193 kcal and among women 1,733 kcal, whereas this was 2,253 kcal among men and 1,941 kcal among women according to the FFQ. Compared with the dietary record, absolute intakes of the macronutrients protein, total fat, and carbohydrates were about 6\% to $7 \%$ higher in the FFQ, whereas alcohol intake was $22 \%$ lower. Mean intakes of all

Table 2. Daily nutrient intakes and Spearman correlation coefficients comparing intakes based on a food frequency questionnaire (FFQ) to intakes based on a 7-day dietary record in survivors of colorectal cancer, from August 2015 to January 2018 , in the southeast of the Netherlands

\section{Intake from \\ Dietary Record Intake from FFQ}

Spearman Correlation Coefficients

Corrected for within-person Difference $^{\mathrm{b}}$ Crude Energy-adjusted variation

\begin{tabular}{|c|c|c|c|c|c|c|}
\hline Nutrients & Mean $\pm S D^{a}$ & Mean \pm SD & Difference $^{\mathrm{b}}$ & Crude & Energy-adjusted & variation $^{c}$ \\
\hline & \multicolumn{6}{|c|}{$\longleftrightarrow$ kcal $\longrightarrow$} \\
\hline Energy & $2,083 \pm 447$ & $2,178 \pm 545$ & 4.6 & 0.55 & - & 0.62 \\
\hline Protein & $77.9 \pm 15.6$ & $83.3 \pm 19.7$ & 6.9 & 0.45 & 0.53 & 0.55 \\
\hline Total fat & $81.0 \pm 20.2$ & $85.7 \pm 30.7$ & 5.8 & 0.49 & 0.49 & 0.58 \\
\hline Saturated fat & $29.7 \pm 9.0$ & $30.9 \pm 12.3$ & 4.0 & 0.54 & 0.56 & 0.62 \\
\hline Monounsaturated fatty acids & $28.0 \pm 7.4$ & $29.9 \pm 11.1$ & 6.8 & 0.43 & 0.38 & 0.53 \\
\hline Polyunsaturated fatty acids & $16.3 \pm 4.8$ & $17.7 \pm 8.2$ & 8.6 & 0.42 & 0.29 & 0.53 \\
\hline Carbohydrates & $214.6 \pm 53.7$ & $227.5 \pm 62.9$ & 6.0 & 0.64 & 0.65 & 0.70 \\
\hline Mono- and disaccharides & $82.4 \pm 31.5$ & $92.4 \pm 39.1$ & 12.1 & 0.60 & 0.64 & 0.65 \\
\hline Polysaccharides & $132.1 \pm 33.8$ & $135.0 \pm 37.9$ & 2.2 & 0.66 & 0.55 & 0.75 \\
\hline Dietary fiber & $21.8 \pm 6.5$ & $26.5 \pm 8.8$ & 21.6 & 0.54 & 0.56 & 0.58 \\
\hline Alcohol & $18.9 \pm 25.8$ & $14.7 \pm 18.3$ & -22.2 & 0.86 & 0.79 & 0.91 \\
\hline Calcium & $793.8 \pm 260.0$ & $920.0 \pm 358.8$ & 15.9 & 0.41 & 0.50 & 0.46 \\
\hline Magnesium & $332.9 \pm 90.3$ & $375.6 \pm 104.5$ & 12.8 & 0.57 & 0.57 & 0.61 \\
\hline Riboflavin & $1.3 \pm 0.4$ & $1.4 \pm 0.4$ & 7.7 & 0.38 & 0.39 & 0.42 \\
\hline Vitamin B-6 & $1.8 \pm 0.6$ & $1.7 \pm 0.5$ & -5.6 & 0.50 & 0.54 & 0.61 \\
\hline Vitamin B-12 & $4.6 \pm 2.7$ & $4.7 \pm 2.3$ & 2.2 & 0.53 & 0.56 & 0.74 \\
\hline Vitamin D & $4.0 \pm 1.9$ & $4.0 \pm 2.0$ & 0.0 & 0.45 & 0.40 & 0.67 \\
\hline Folate & $231.4 \pm 62.9$ & $251.4 \pm 75.0$ & 8.6 & 0.49 & 0.47 & 0.57 \\
\hline Folic acid & $24.2 \pm 44.0$ & $7.2 \pm 16.5$ & -70.2 & 0.13 & 0.26 & 0.14 \\
\hline Dietary folate equivalents & $272.4 \pm 97.7$ & $263.5 \pm 7.9$ & -3.3 & 0.43 & 0.39 & 0.47 \\
\hline & \multicolumn{6}{|c|}{$\longleftrightarrow$ energy $\longrightarrow$} \\
\hline Protein & $15.9 \pm 2.3$ & $16.3 \pm 2.6$ & 2.5 & 0.60 & - & 0.74 \\
\hline Total fat & $35.2 \pm 5.4$ & $34.9 \pm 6.1$ & -0.9 & 0.47 & - & 0.56 \\
\hline Carbohydrate & $43.3 \pm 5.7$ & $44.1 \pm 6.5$ & 1.8 & 0.64 & - & 0.75 \\
\hline
\end{tabular}

${ }^{c}$ Corrected for within-person day-to-day variation of the 7-day dietary records. 
micronutrients except vitamin B-6, folic acid, and dietary folate equivalents were higher when measured by the FFQ. When comparing the intake of the macronutrients protein, total fat, and carbohydrates according to their energy percentages, both methods differed less than $3 \%$ (Table 2).

Table 3 shows the means and standard deviations for the intake of food groups. The intake of bread; cheese; cereals and cereal products; vegetables; meat, meat products, and poultry; and fats, oils, and savory sauces differed $\leq 5 \%$ between the FFQ and dietary record. The largest dissimilarities between the two methods were found for savory bread spreads, soy products and vegetarian products, and mixed dishes, which were all estimated $>40 \%$ lower by the FFQ. Bland-Altman plots (Figure 1) illustrate that total energy and macronutrient intakes were overestimated by the FFQ compared with the dietary record (mean difference $>0$ for both men and women). The plots also show that the disagreement between methods appears to increase with higher intakes, especially for men.

\section{Correlations between Methods}

Spearman correlation coefficients for nutrients and total energy, corrected for within-person variation, ranged between 0.14 and 0.91 (median=0.60) and, adjusted for energy, between 0.26 and 0.79 (median $=0.53$ ). Correlations corrected for within-person variation $>0.50$ were found for 15 of 19 nutrients, with highest agreement for vitamin B-12 (0.74), polysaccharides (0.75), and alcohol (0.91) (Table 2).

Spearman correlation coefficients for food groups, corrected for within-person variation, ranged between 0.31 and 0.99 (median=0.62). Correlations corrected for

Table 3. Daily food group intakes and Spearman correlation coefficients comparing intakes based on a food frequency questionnaire (FFQ) to intakes based on a 7-day dietary record in survivors of colorectal cancer, from August 2015 to January 2018 in the southeast of the Netherlands

\begin{tabular}{|c|c|c|c|c|c|}
\hline \multirow[b]{2}{*}{ Food groups $^{a}$} & \multicolumn{3}{|c|}{$\begin{array}{l}\text { Intake From } \\
\text { Dietary Record Intake From FFQ }\end{array}$} & \multicolumn{2}{|c|}{$\begin{array}{c}\text { Spearman Correlation } \\
\text { Coefficients }\end{array}$} \\
\hline & Mean $\pm S^{b}$ & Mean \pm SD & $\begin{array}{l}\% \\
\text { difference }^{c}\end{array}$ & Crude & $\begin{array}{l}\text { Corrected for } \\
\text { within- person } \\
\text { variation }^{d}\end{array}$ \\
\hline Bread & $151.0 \pm 56.6$ & $153.2 \pm 66.2$ & 1.5 & 0.70 & 0.77 \\
\hline Savory bread spreads & $5.9 \pm 4.2$ & $3.2 \pm 6.4$ & -45.8 & 0.51 & 0.61 \\
\hline Cheese & $31.2 \pm 18.4$ & $31.1 \pm 27.5$ & -0.3 & 0.53 & 0.63 \\
\hline Milk and milk products & $175.8 \pm 125.7$ & $223.3 \pm 141.7$ & 27.0 & 0.57 & 0.63 \\
\hline Eggs & $21.2 \pm 16.4$ & $18.8 \pm 14.7$ & -11.3 & 0.41 & 0.58 \\
\hline Cereals and cereal products & $51.9 \pm 42.8$ & $49.7 \pm 38.8$ & -4.2 & 0.65 & 0.96 \\
\hline Soups & $85.0 \pm 66.2$ & $77.4 \pm 92.5$ & -8.9 & 0.42 & 0.53 \\
\hline Potatoes & $90.1 \pm 50.1$ & $120.2 \pm 65.1$ & 33.4 & 0.54 & 0.99 \\
\hline Vegetables & $139.1 \pm 74.3$ & $141.0 \pm 82.5$ & 1.4 & 0.46 & 0.57 \\
\hline Legumes & $23.9 \pm 18.1$ & $18.0 \pm 19.7$ & -24.7 & 0.21 & 0.31 \\
\hline Meat, meat products and poultry & $105.1 \pm 49.6$ & $100.5 \pm 50.7$ & -4.4 & 0.68 & 0.87 \\
\hline Fish & $32.9 \pm 30.5$ & $24.9 \pm 22.3$ & -24.3 & 0.59 & 0.96 \\
\hline Soy products and vegetarian products & $23.4 \pm 65.0$ & $11.6 \pm 49.2$ & -50.4 & 0.77 & 0.87 \\
\hline Mixed dishes & $59.2 \pm 44.0$ & $29.9 \pm 29.9$ & -49.5 & 0.43 & 0.79 \\
\hline Fats, oils and savory sauces & $47.2 \pm 18.6$ & $45.6 \pm 28.9$ & -3.4 & 0.29 & 0.43 \\
\hline Fruits & $136.5 \pm 90.9$ & $178.4 \pm 130.8$ & 30.7 & 0.54 & 0.61 \\
\hline Sugar, sweets and sweet sauces & $28.5 \pm 23.7$ & $30.4 \pm 26.0$ & 6.7 & 0.62 & 0.68 \\
\hline Nuts, seeds and snacks & $27.8 \pm 18.2$ & $25.3 \pm 16.8$ & -9.0 & 0.28 & 0.39 \\
\hline Pastry and cookies & $40.6 \pm 35.8$ & $28.2 \pm 22.4$ & -30.5 & 0.48 & 0.59 \\
\hline Alcoholic and nonalcoholic beverages & $1,554.0 \pm 580.4$ & $1,452.9 \pm 542.3$ & -6.5 & 0.56 & 0.60 \\
\hline
\end{tabular}

${ }^{\mathrm{a}}$ Food groups were adopted from the Dutch Food Composition Database.

${ }^{b_{S D}}=$ standard deviation

${ }^{c}$ Formula for \% difference: ((intake FFQ-intake dietary record)/intake dietary record) $\times 100$

${ }^{d}$ Corrected for within-person day-to-day variation of the 7-day dietary records. 

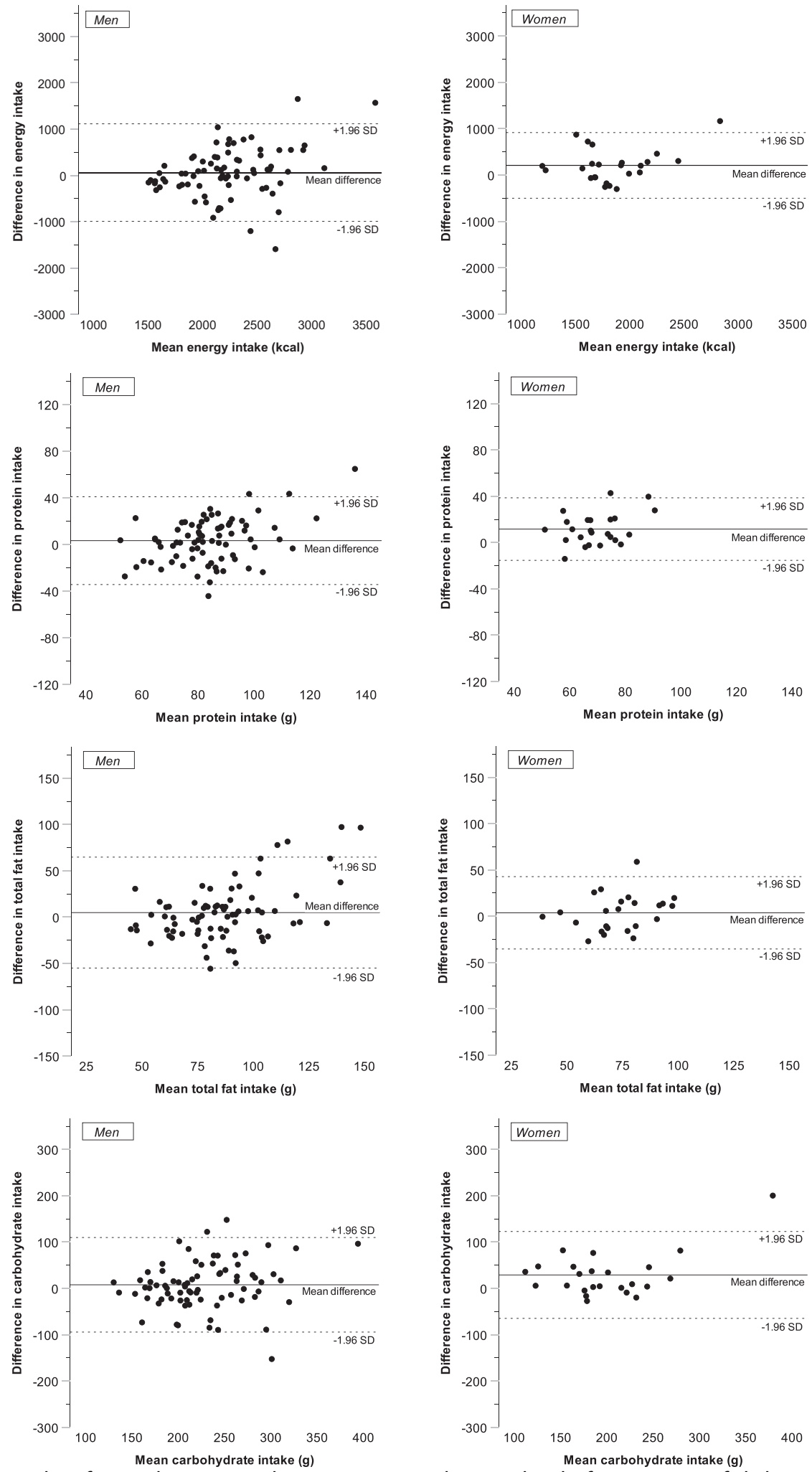

Figure 1. Bland-Altman plots for total energy and macronutrients showing level of agreement of daily intakes based on a food frequency questionnaire (FFQ) and a 7-day dietary record, respectively, in survivors of colorectal cancer, from August 2015 to January 2018 in the southeast of the Netherlands. $y$-axis: (FFQ intake-dietary record intake), $x$-axis: (FFQ intake+dietary record intake) $/ 2 . \mathrm{SD}=$ standard deviation. 
Table 4. Comparison of quintile classifications by a food frequency questionnaire (FFQ) and a 7-day dietary record in survivors of colorectal cancer, from August 2015 to January 2018, in the southeast of the Netherlands

FFQ-Based Quintiles

\begin{tabular}{|c|c|c|c|c|c|c|c|c|c|}
\hline \multirow[b]{2}{*}{$\begin{array}{l}\text { Nutrient intake/day } \\
\text { from dietary record }\end{array}$} & \multicolumn{5}{|c|}{ FFQ-Based Quintiles } & \multicolumn{3}{|c|}{ Quintile Classifications } & \multirow[b]{2}{*}{$\begin{array}{l}\text { Linearly } \\
\text { weighted } \kappa\end{array}$} \\
\hline & $\begin{array}{l}Q^{a} 1 \\
(n=20)\end{array}$ & $\begin{array}{l}\text { Q } 2 \\
(n=20)\end{array}$ & $\begin{array}{l}\text { Q } 3 \\
(n=20)\end{array}$ & $\begin{array}{l}\text { Q } 4 \\
(n=20)\end{array}$ & $\begin{array}{l}\text { Q } 5 \\
(n=20)\end{array}$ & Exact & Adjacent & Opposite & \\
\hline & & 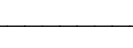 & $-k c a l-$ & & $\longrightarrow$ & $\longleftarrow$ & $n-$ & $\longrightarrow$ & \\
\hline Energy & 1,756 & 1,989 & 2,090 & 2,155 & 2,424 & 41 & 38 & 2 & 0.44 \\
\hline Protein & 69.5 & 75.2 & 78.4 & 79.7 & 87.2 & 38 & 34 & 3 & 0.36 \\
\hline Total fat & 70.8 & 76.4 & 78.4 & 86.9 & 88.0 & 26 & 43 & 1 & 0.29 \\
\hline Saturated fat & 25.0 & 29.2 & 30.5 & 30.7 & 36.8 & 38 & 36 & 1 & 0.39 \\
\hline Monounsaturated fatty acids & 25.4 & 28.1 & 27.4 & 31.5 & 31.1 & 29 & 34 & 2 & 0.24 \\
\hline Polyunsaturated fatty acids & 14.0 & 15.5 & 18.1 & 15.2 & 17.4 & 31 & 33 & 5 & 0.21 \\
\hline Carbohydrate & 183.5 & 206.0 & 214.4 & 232.4 & 235.7 & 33 & 45 & 1 & 0.41 \\
\hline Mono- and disaccharides & 59.2 & 71.9 & 90.3 & 91.7 & 100.6 & 39 & 43 & 1 & 0.46 \\
\hline Polysaccharides & 115.4 & 120.3 & 133.9 & 143.0 & 146.5 & 38 & 35 & 3 & 0.38 \\
\hline Dietary fiber & 16.9 & 22.8 & 23.0 & 24.2 & 26.8 & 39 & 41 & 2 & 0.41 \\
\hline Alcohol & 0.0 & 9.8 & 13.9 & 20.3 & 47.7 & 51 & 33 & 0 & 0.58 \\
\hline Calcium & 621.3 & 744.1 & 775.6 & 917.2 & 915.2 & 27 & 49 & 3 & 0.33 \\
\hline Magnesium & 279.5 & 314.8 & 339.8 & 338.3 & 390.5 & 37 & 38 & 2 & 0.39 \\
\hline Riboflavin & 1.84 & 1.98 & 2.11 & 2.14 & 2.22 & 29 & 41 & 4 & 0.28 \\
\hline Vitamin B-6 & 1.95 & 1.98 & 2.21 & 2.50 & 2.55 & 36 & 41 & 4 & 0.38 \\
\hline Vitamin B-12 & 4.30 & 4.00 & 4.84 & 5.14 & 7.66 & 41 & 34 & 3 & 0.43 \\
\hline Vitamin D & 3.32 & 3.56 & 4.07 & 4.55 & 5.31 & 32 & 33 & 2 & 0.26 \\
\hline Folate & 195.4 & 217.6 & 239.9 & 247.1 & 262.2 & 35 & 37 & 3 & 0.33 \\
\hline Folic acid & 22.9 & 9.7 & 38.7 & 14.3 & 30.4 & 26 & 34 & 6 & 0.18 \\
\hline Dietary folate equivalents & 233.7 & 264.9 & 259.2 & 291.7 & 311.1 & 31 & 41 & 6 & 0.28 \\
\hline
\end{tabular}

${ }^{\mathrm{a}} \mathrm{Q}=$ quintile

b"Exact" defined as classification into the exact same quintile by both methods; "Adjacent" defined as classification into one of the adjacent quintiles (eg, second quintile for FFQ and third quintile for dietary record); "Opposite" defined as classification into the extreme quintiles (ie, first quintile for FFQ and fifth quintile for dietary record, and vice versa).

within-person variation $>0.50$ were found for 17 of 20 food groups, with highest agreement for fish (0.96), cereals and cereal products (0.96), and potatoes (0.99) (Table 3).

\section{Agreement between Quintile Distributions}

Table 4 shows the mean nutrient intakes from the dietary record in quintiles of intake based on the FFQ. Intake of most nutrients steadily increased with increasing quintiles, except for folic acid, which showed no clear pattern. When quintiles based on the FFQ were compared with quintiles based on the dietary record, on average $35 \%$ (range $=26 \%$ to $51 \%$ ) of participants were classified into the exact same quintile, $38 \%$ (range $=33 \%$ to $49 \%$ ) into the adjacent quintile, and only $3 \%$ (range $=0 \%$ to $6 \%$ ) into the opposite quintile (quintile 1 vs quintile 5). Cohen's linearly weighted $\kappa$ ranged between 0.18 (folic acid) and 0.58 (alcohol), with a median of 0.37 .

\section{WCRF/AICR Dietary Recommendations}

Figure 2 illustrates the distribution of scores on the WCRF/ AICR dietary recommendations according to each of the methods for the total population and for men and women

Figure 2. Distribution of scoring on the World Cancer Research Fund/American Institute for Cancer Research dietary recommendations according to a dietary record (left side) and an FFQ (right side) in an FFQ validation study among survivors of colorectal cancer, in total (A), men (B), and women (C), from August 2015 to January 2018 in the southeast of the Netherlands. FFQ=food frequency questionnaire; $\mathrm{pt}=$ points. 
A

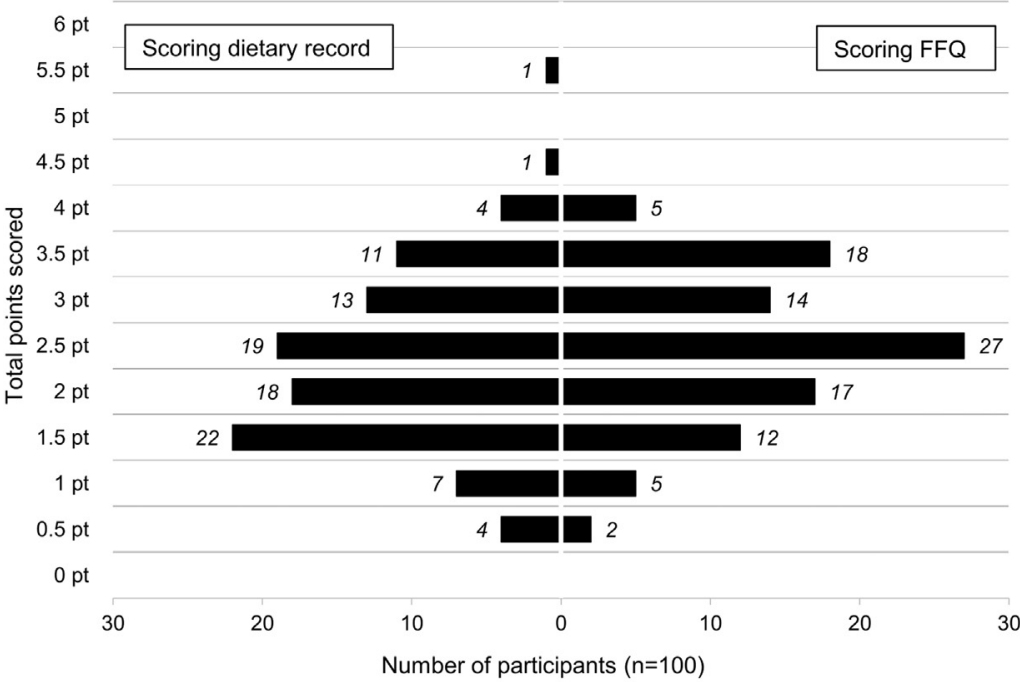

B

Number of participants $(n=100)$

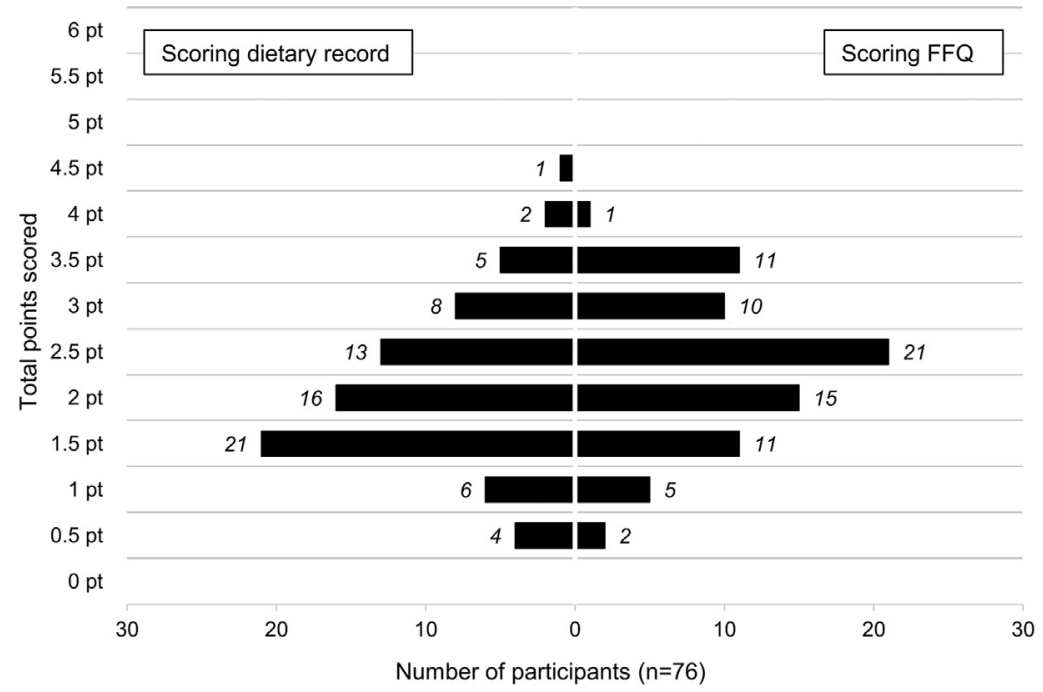

C

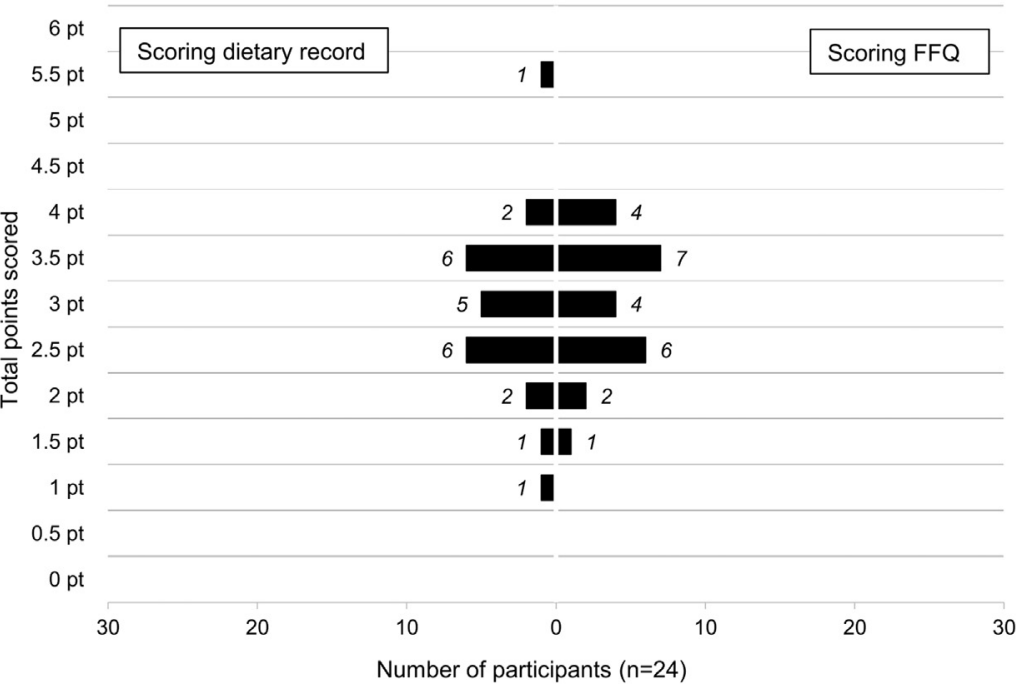


separately. The Spearman correlation between the total scores was 0.53 . A median score of 2.5 (range $=0.5$ to 4.0 ) was obtained by the FFQ and a median score of 2.0 (range $=0.5$ to 5.5) by the dietary record. In addition, women scored a median of 3.0 points based on both methods, and men scored a median of 2.5 points based on the FFQ and a median of 2.0 points on the dietary record. Linearly weighted $\kappa$ ranged from 0.23 (dietary fiber intake) to 0.59 (alcohol intake) (Table 5). The recommendation to not consume alcohol showed the highest Spearman correlation (0.88) between methods, whereas the lowest correlation $(0.50)$ was observed for the recommendation to eat a diet high in plant foods.

\section{DISCUSSION}

This study assessed the validity of an FFQ against a 7-day dietary record in a population of survivors of CRC. The FFQ performed moderately to well when evaluating the Spearman correlation coefficients for nutrients and food groups. Correlations $>0.50$ were found for total energy, all macronutrients, and most micronutrients and food groups. The FFQ performed less well (correlations $<0.50$ ) for the micronutrients folic acid, riboflavin, calcium, and dietary folate equivalents, and the food groups legumes; nuts, seeds, and snacks; and fats, oils, and savory sauces. Although $\kappa$ coefficients were relatively low $(<0.40)$ for protein, total fat, minerals such as calcium and magnesium, and riboflavin and vitamin B-6, for all these nutrients approximately $70 \%$ to $80 \%$ of participants were classified in the exact or adjacent quintile and very few $(\leq 4 \%)$ in the opposite quintile.

Correlation coefficients observed in the current study are comparable to previous findings. Results could not be compared with other FFQ validation studies among adult survivors of cancer because this was the first validation study in this population. The FFQ used in the current study was based on an FFQ designed for a population-based study on type 2 diabetes, where total energy and macronutrient correlations of 0.38 to 0.56 and food group correlations of 0.30 to 0.69 were observed when evaluated against one to five 24-hour dietary recalls and biomarkers. ${ }^{27}$ The European Prospective Investigation into Cancer and Nutrition observed crude total energy and macronutrient correlations of 0.51 to 0.71 for men and 0.51 to 0.66 for women, and food group correlations of 0.21 to 0.78 for men and 0.31 to 0.87 for women when evaluating the Dutch European Prospective Investigation into Cancer and Nutrition FFQ against 12 monthly 24-hour recalls. ${ }^{28,29}$

FFQs and dietary records are prone to several types of measurement bias that could have influenced the results of the current study. FFQs are known to have relatively high systematic bias because dietary intake tends to be overestimated when a large number of fixed food items are presented and need to be recalled over a long period of time. ${ }^{30}$ Dietary records are more prone to random measurement error caused by within-person day-to-day variation. ${ }^{5}$ The bias of social desirability affects both methods. Individuals are, to a greater or lesser extent, influenced by social norms and values when reporting their dietary intake. ${ }^{31}$ Furthermore, participants may simply forget or find it too bothersome to report certain items, which may lead to underreporting in both an FFQ and dietary record. ${ }^{31}$ Another type of bias, applicable to dietary records, is the altering of the diet during the period of recording. ${ }^{31}$ Inevitably, participants become increasingly aware of their dietary behaviors when recording their diet, and this can, consciously or unconsciously, lead to changes in "normal" eating behaviors. All aforementioned types of bias are difficult to avoid, and estimating dietary intake therefore remains complex. ${ }^{32}$ Moreover, when a true "gold standard" is lacking, it is specifically challenging to identify the exact source (FFQ or dietary record), magnitude, and the direction of bias. The designs of both methods differ in their purpose and perfect correlation would never be obtained. Although the within-person variation in the dietary record was accounted for by calculating the adjusted Spearman coefficients, person-related propensity to over- or underestimate the intake of specific foods cannot be completely ruled out. ${ }^{5}$ However, the correlated errors of FFQs and dietary records are believed to be relatively low, ${ }^{4}$ and the observed agreement between methods is likely to be true agreement instead of an agreement of errors.

For folic acid in particular, correlations were low and the agreement between quintiles was weak. This was likely due to differences between the methods regarding the selection of underlying food items from the Dutch Food Composition Database. Folic acid is only found in a limited number of foods, such as folic acid-fortified (low-fat) margarines and breakfast cereals, but there is large variety in folic acid content between those foods. The selection of a different food between the methods could easily have led to low agreement because the selected answer option in the FFQ could be low in folic acid, whereas the reported or coded food item in the dietary record could be high in folic acid. In addition, the estimated FFQ intake of the food group mixed dishes was 49.5\% lower than the intake according to the dietary record. This could have been caused by a difference in the assessment of mixed dishes by both methods. Mixed dishes may have been recorded and coded as mixed dishes or as the separate ingredients in the dietary records, whereas they were likely reported as mixed dishes in the FFQ because seven different types of mixed dishes were included. The food groups with low agreement indicate where the FFQ could potentially be improved for future use.

Regarding the WCRF/AICR dietary recommendations, the correlation of 0.53 between the total scores of both methods was considered moderate to good. Higher scores were obtained by the FFQ compared with the dietary record, and $\kappa$ coefficients for the distribution of scoring $0,0.5$, or 1 point were below 0.40 for the individual recommendations on energy density, fruit and vegetables, dietary fiber, and red and processed meat. In contrast, correlation coefficients between individual recommendations were all $\geq 0.50$. Thus, when ranking subjects according to their adherence scores, both methods showed moderate to good agreement, whereas the exact number of points scored was less comparable between methods.

The Bland-Altman plots implied that there was increased disagreement in the higher ranges of intake, especially for men. Extreme intakes may more likely be exposed when recording actual intake in the dietary record, ${ }^{33}$ whereas FFQs represent a longer period of reference with subjects summarizing usual intake. As the Bland-Altman plots showed unadjusted intakes, this divergence between methods could have led to the greater disagreement for higher intakes. 
Table 5. Adherence to the WCRF/AICR ${ }^{a}$ dietary recommendations according to a food frequency questionnaire (FFQ) and a 7day dietary record in survivors of colorectal cancer, from August 2015 to January 2018 in the southeast of the Netherlands

\begin{tabular}{|c|c|c|c|c|c|c|c|c|}
\hline \multirow{2}{*}{$\begin{array}{l}\text { WCRF/AICR dietary } \\
\text { recommendations } \\
2018^{\text {b }} \\
\end{array}$} & \multirow[b]{2}{*}{ Operationalization $^{c}$} & \multirow[b]{2}{*}{ Scoring } & \multicolumn{2}{|c|}{ Dietary Record } & \multicolumn{2}{|r|}{ FFQ } & \multirow{2}{*}{$\begin{array}{l}\text { Linearly } \\
\text { weighted } \\
\kappa^{\mathrm{e}} \\
\end{array}$} & \multirow{2}{*}{$\begin{array}{l}\text { Spearman } \\
\text { correlation }^{\mathrm{f}} \\
\text { coefficient }^{\mathrm{f}}\end{array}$} \\
\hline & & & $\mathbf{n}$ & $\begin{array}{l}\text { Mean } \\
\text { intake } \pm S D^{d} \\
\end{array}$ & $\mathbf{n}$ & $\begin{array}{l}\text { Mean } \\
\text { intake } \pm S D\end{array}$ & & \\
\hline \multirow{4}{*}{$\begin{array}{l}\text { Limit consumption } \\
\text { of "fast foods" and } \\
\text { other processed } \\
\text { foods high in fat, } \\
\text { starches, or sugars. }\end{array}$} & Energy density of diet: & & & & & & 0.29 & 0.54 \\
\hline & $\leq 125$ kcal; 100 g/day & 1 & 5 & $121.0 \pm 2.8$ & 8 & $105.6 \pm 9.4$ & & \\
\hline & $>125-<175 \mathrm{kcal} ; 100 \mathrm{~g} /$ day & 0.5 & 49 & $158.7 \pm 11.9$ & 58 & $151.2 \pm 15.6$ & & \\
\hline & $\geq 175$ kcal; 100 g/day & 0 & 46 & $196.8 \pm 17.1$ & 34 & $195.0 \pm 20.2$ & & \\
\hline \multirow{4}{*}{$\begin{array}{l}\text { Do not consume } \\
\text { sugar-sweetened } \\
\text { drinks. }\end{array}$} & Sugar sweetened drink intake: & & & & & & 0.41 & 0.52 \\
\hline & $0 \mathrm{~g} /$ day & 1 & 25 & $0.0 \pm 0.0$ & 11 & $0.0 \pm 0.0$ & & \\
\hline & $>0-\leq 250 \mathrm{~g} /$ day & 0.5 & 62 & $81.8 \pm 65.3$ & 74 & $76.1 \pm 61.3$ & & \\
\hline & $>250 \mathrm{~g} /$ day & 0 & 13 & $356.9 \pm 95.5$ & 15 & $446.1 \pm 203.5$ & & \\
\hline \multirow{4}{*}{$\begin{array}{l}\text { Eat a diet high in all } \\
\text { types of plant foods } \\
\text { including at least } \\
\text { five portions (at } \\
\text { least } 400 \mathrm{~g} \text { in total) } \\
\text { of a variety of } \\
\text { nonstarchy } \\
\text { vegetables and fruit } \\
\text { every day. }\end{array}$} & Fruit and vegetable intake: & & & & & & 0.32 & 0.50 \\
\hline & $\geq 400$ g/day & 1 & 18 & $456.6 \pm 47.9$ & 23 & $538.4 \pm 147.4$ & & \\
\hline & $\geq 200-<400$ g/day & 0.5 & 45 & $283.4 \pm 60.9$ & 53 & $277.9 \pm 53.9$ & & \\
\hline & $<200$ g/day & 0 & 37 & $122.2 \pm 54.3$ & 24 & $114.7 \pm 44.3$ & & \\
\hline \multirow{4}{*}{$\begin{array}{l}\text { Consume a diet that } \\
\text { provides at least } 30 \\
\text { g/day of fiber from } \\
\text { food sources. }\end{array}$} & Dietary fiber intake: & & & & & & 0.23 & 0.52 \\
\hline & $\geq 30$ g/day & 1 & 10 & $34.0 \pm 3.6$ & 25 & $36.9 \pm 9.9$ & & \\
\hline & $\geq 15-<30 \mathrm{~g} /$ day & 0.5 & 74 & $22.1 \pm 4.1$ & 70 & $23.8 \pm 3.7$ & & \\
\hline & $<15$ g/day & 0 & 16 & $13.0 \pm 2.0$ & 5 & $11.7 \pm 3.2$ & & \\
\hline \multirow{3}{*}{$\begin{array}{l}\text { If you eat red meat, } \\
\text { limit consumption } \\
\text { to no more than } \\
\text { about three }\end{array}$} & $\begin{array}{l}\text { Red and processed meat } \\
\text { intake: }\end{array}$ & & & & & & 0.34 & $\begin{array}{l}0.55 \text { (red) } \\
0.62 \text { (processed) }\end{array}$ \\
\hline & $<500 \mathrm{~g}$ red meat/wk and & 1 & 6 & $16.7 \pm 30.3$ & 2 & $322.8 \pm 93.0$ & & \\
\hline & $<3 \mathrm{~g}$ processed meat/day & & & $0.5 \pm 0.8$ & & $1.3 \pm 1.7$ & & \\
\hline portions per week. & $<500 \mathrm{~g}$ red meat/wk and & 0.5 & 34 & $257.6 \pm 139.3$ & 53 & $245.8 \pm 143.4$ & & \\
\hline $\begin{array}{l}\text { Three portions is } \\
\text { equivalent to about }\end{array}$ & $\begin{array}{l}\geq 3-<50 \mathrm{~g} \text { processed } \\
\text { meat/day }\end{array}$ & & & $26.3 \pm 13.3$ & & $26.6 \pm 13.3$ & & \\
\hline $\begin{array}{l}350 \text { to } 500 \mathrm{~g} \\
\text { cooked weight of } \\
\text { red meat. Consume } \\
\text { very little, if any, } \\
\text { processed meat. }\end{array}$ & $\begin{array}{l}\geq 500 \mathrm{~g} \text { red } \text { meat/wk or } \\
\geq 50 \mathrm{~g} \text { processed meat/day }\end{array}$ & 0 & 60 & $\begin{array}{c}403.6 \pm 239.7 \\
66.3 \pm 31.6\end{array}$ & 45 & $\begin{array}{c}524.2 \pm 224.3 \\
61.2 \pm 31.1\end{array}$ & & \\
\hline \multicolumn{3}{|c|}{ For cancer prevention, Alcohol intake ${ }^{g}$ : } & & & & & 0.59 & 0.88 \\
\hline it is best not to & $0 \mathrm{~g} /$ day & 1 & 19 & $0.0 \pm 0.0$ & 3 & $0.0 \pm 0.0$ & & \\
\hline \multirow[t]{2}{*}{ drink alcohol. } & $>0-\leq 10 \mathrm{~g} /$ day & 0.5 & 28 & $4.0 \pm 2.8$ & 49 & $3.3 \pm 3.1$ & & \\
\hline & $>10 \mathrm{~g} /$ day & 0 & 53 & $33.6 \pm 28.1$ & 48 & $27.4 \pm 19.6$ & & \\
\hline
\end{tabular}

${ }^{a}$ WCRF/AICR $=$ World Cancer Research Fund/American Institute for Cancer Research.

${ }^{b}$ Spearman correlation between total scores FFQ and dietary record $=0.53$. Median score dietary record $=2.0$. Median $s c o r e ~ F F Q=2.5$.

'Operationalization based on the 2018 and 2007 recommendations. ${ }^{13,14}$

${ }^{\mathrm{d}} \mathrm{SD}=$ standard deviation.

eLinearly weighted $\kappa$ calculated for scoring $0,0.5$, or 1 point on the WCRF/AICR score compared for both methods.

${ }^{\mathrm{f} C}$ rude Spearman correlations calculated between absolute intakes of both methods for each recommendation.

${ }^{g}$ Calculated as the nutrient alcohol. For the FFQ, the calculation of alcohol intake also comprised food products containing alcohol (eg, tiramisu, chocolate pralines), although this was not the case for the dietary records. As a result, 12 of 15 participants in total who reported to not have consumed alcoholic drinks in the past month were misclassified in the middle category because of the consumption of foods containing alcohol. 
Our study had several strengths and also limitations. An important strength of the current study involves the comparison of the FFQ with a 7-day dietary record, which is a suitable method to evaluate the validity of an FFQ. ${ }^{3}$ Another strength involves the high quality and completeness of the data, which was achieved by the thorough instructions provided by trained research dietitians during the home visits. In addition, all required details on dietary intake were obtained by checking the instruments directly after completion and contacting participants by telephone if additional clarification was needed. Additional quality control checks were performed during data entry and data cleaning. Furthermore, different aspects of validity of the FFQ were investigated by comparing absolute intakes as well as Spearman rank correlations, and agreement based on $\kappa$ coefficients and BlandAltman plots.

A limitation of the current study may be that the validation population might consist of the more motivated and healthy participants because they voluntarily consented to participate in both the EnCoRe and the validation study. It is unknown whether these participants were indeed more likely to report with less measurement error than the average survivor of CRC. Differences between responders and nonresponders were small but when interpreting the results, it must be considered that participants were more often men and had a lower mean age than the overall population. Another potential limitation is that the dietary record was completed approximately 2 weeks before the FFQ, although for evaluation purposes it is often preferred to administer the instrument to be evaluated before the reference instrument. ${ }^{3}$ In the current study, however, reference periods of both methods would not have overlapped when the FFQ had been administered first. Keeping a dietary record could have made participants more aware of their dietary intake. On the one hand, this may have influenced the response to the FFQ, causing correlation coefficients to be somewhat increased. One the other hand, the increased awareness of intake could have led to a more accurate completion of the FFQ.

To our knowledge, the current study was the first FFQ validation study among adult survivors of cancer. The results contribute to the existing literature on the evaluation of FFQs and are important for the general understanding of the agreement between FFQs and 7-day dietary records in populations of survivors of cancer. Moreover, the results are relevant in meta-analyses to pool data with other cohorts of survivors of CRC using FFQs.

\section{CONCLUSIONS}

The current study investigated the validity of an FFQ and showed that ranking of subjects according to their nutrient and food group intakes was moderate to good (most Spearman correlations $>0.50$ ) in comparison with a 7-day dietary record. Direct comparison of absolute intakes between both methods is not justified because potential differences are more likely a result of the difference in assessment method. Instead, the results could be used to rank subjects according to their intake in the current study and in the pooling of dietary data with other cohorts of survivors of CRC.

\section{References}

1. Thompson FE, Kirkpatrick SI, Subar AF, et al. The National Cancer Institute's dietary assessment primer: A resource for diet research. J Acad Nutr Diet. 2015;115(12):1986-1995.

2. Willett WC. Food frequency methods. In: Nutritional Epidemiology. Vol 40. 3rd ed. New York, NY: Oxford University Press; 2013.

3. Cade J, Thompson R, Burley V. Warm D. Development, validation and utilisation of food-frequency questionnaires-A review. Public Health Nutr. 2002;5(4):567-587.

4. Willett WC, Lenart E. Reproducibility and validity of food frequency questionnaires. In: Nutritional Epidemiology. Vol 40. 3rd ed. New York, NY: Oxford University Press; 2013.

5. Willett WC, Baranowski T. 24-Hour recall and diet record methods. In: Nutritional Epidemiology. Vol 40. 3rd ed. New York, NY: Oxford University Press; 2013.

6. Goldbohm RA, van den Brandt PA, Brants HA, et al. Validation of a dietary questionnaire used in a large-scale prospective cohort study on diet and cancer. Eur J Clin Nutr. 1994;48(4):253-265.

7. Shatenstein B, Nadon S, Godin C, Ferland G. Development and validation of a food frequency questionnaire. Can J Diet Pract Res. 2005;66(2):67-75.

8. McNaughton SA, Marks GC, Gaffney P. Williams G, Green A. Validation of a food-frequency questionnaire assessment of carotenoid and vitamin E intake using weighed food records and plasma biomarkers: The method of triads model. Eur J Clin Nutr. 2005;59(2): 211-218.

9. Blanchard CM, Courneya KS, Stein K. Cancer survivors' adherence to lifestyle behavior recommendations and associations with healthrelated quality of life: Results from the American Cancer Society's SCS-II. J Clin Oncol. 2008;26(13):2198-2204.

10. Van Blarigan EL, Meyerhardt JA. Role of physical activity and diet after colorectal cancer diagnosis. J Clin Oncol. 2015;33(16): 1825-1834.

11. van Zutphen M, Kampman E, Giovannucci EL, van Duijnhoven FJB Lifestyle after colorectal cancer diagnosis in relation to survival and recurrence: A review of the literature. Curr Colorectal Cancer Rep. 2017;13(5):370-401.

12. Romaguera D, Vergnaud AC, Peeters PH, et al. Is concordance with World Cancer Research Fund/American Institute for Cance Research guidelines for cancer prevention related to subsequent risk of cancer? Results from the EPIC study. Am J Clin Nutr. 2012;96(1):150-163.

13. World Cancer Research Fund International/American Institute for Cancer Research. Food, Nutrition, Physical Activity, and the Prevention of Cancer: A Global Perspective. Washington, DC: AICR; 2007.

14. World Cancer Research Fund International/American Institute for Cancer Research. Diet, nutrition, physical activity and cancer: A global perspective. dietandcancerreport.org. Published 2018. Accessed August 12, 2019.

15. Winkels RM, van Lee L, Beijer S, et al. Adherence to the World Cancer Research Fund/American Institute for Cancer Research lifestyle rec ommendations in colorectal cancer survivors: Results of the PROFILES registry. Cancer Med. 2016;5(9):2587-2595.

16. Breedveld-Peters JJL, Koole JL, Muller-Schulte E, et al. Colorecta cancers survivors' adherence to lifestyle recommendations and cross-sectional associations with health-related quality of life. $\mathrm{Br}$ Nutr. 2018;120(2):188-197.

17. van Roekel EH, Bours MJ, de Brouwer CP, et al. The applicability o the international classification of functioning, disability, and health to study lifestyle and quality of life of colorectal cancer survivors. Cancer Epidemiol Biomarkers Prev. 2014;23(7):1394-1405.

18. RIVM/Voedingscentrum. Dutch Food Composition (NEVO) Table 2011 The Hague, the Netherlands: Netherlands Nutrition Center; 2011.

19. van Rossum CT, Fransen HP, Verkaik-Kloosterman J, BuurmaRethans EJ, Ocke MC. Dutch National Food Consumption Survey 2007 2010: Diet of Children and Adults Aged 7 to 69 Years. Bilthoven, the Netherlands: National Institute of Public Health and the Environment (RIVM); 2011.

20. van der Heijden LDHV; Wageningen University and TNO Voeding. Maten, Gewichten en Codenummers. Zeist, the Netherlands: Bohn Stafleu van Loghum; 2003.

21. Compl-eat [computer program]. Wageningen, the Netherlands: Wageningen University \& Research; 2018. 
22. Rosner B, Glynn RJ. Interval estimation for rank correlation coefficients based on the probit transformation with extension to measurement error correction of correlated ranked data. Stat Med. 2007;26(3):633-646.

23. Willett WC, Howe GR, Kushi LH. Adjustment for total energy intake in epidemiologic studies. Am J Clin Nutr. 1997;65(4 Suppl):1220S1228S. discussion 1229S-1231S.

24. Portney LG, Watkins MP. Foundations of Clinical Research: Applications to Practice. Philadelphia, PA: F.A. Davis Company/Publishers; 2015.

25. IBM SPSS Statistics for Windows [computer program]. Version 24.0. Armonk, NY: IBM Corp; Released 2016.

26. SAS for Windows [computer program]. Version 9.4. Cary, NC: SAS Institute Inc; 2014.

27. van Dongen MC, Wijckmans-Duysens NEG, den Biggelaar LJ, et al. The Maastricht FFQ: Development and validation of a comprehensive food frequency questionnaire for the Maastricht study. Nutrition. 2018;62:39-46.

28. Ocke MC, Bueno-de-Mesquita HB, Goddijn HE, et al. The Dutch EPIC food frequency questionnaire. I. Description of the questionnaire and relative validity and reproducibility for food groups. Int J Epidemiol. 1997;26(Suppl 1):S37-48.
29. Ocke MC, Bueno-de-Mesquita HB, Pols MA, Smit HA, van Staveren WA, Kromhout D. The Dutch EPIC food frequency questionnaire. II. Relative validity and reproducibility for nutrients. Int J Epidemiol. 1997;26(Suppl 1):S49-58.

30. Thompson FE, Subar AF. Chapter 1-Dietary assessment methodology. In: Coulston AM, Boushey CJ, Ferruzzi MG, Delahanty LM, eds. Nutrition in the Prevention and Treatment of Disease (Fourth Edition). London, UK: Academic Press; 2017:5-48.

31. Macdiarmid J, Blundell J. Assessing dietary intake: Who, what and why of under-reporting. Nutr Res Rev. 1998;11(2):231-253.

32. Kipnis V, Midthune D, Freedman L, et al. Bias in dietary-report instruments and its implications for nutritional epidemiology. Public Health Nutr. 2002;5(6a):915-923.

33. Willett WC. Nature of variation in diet. In: Nutritional Epidemiology. Vol 40. 3rd ed. New York, NY: Oxford University Press; 2013.

For more information on the subject discussed in this article, see Sites in Review on page 333.

\section{AUTHOR INFORMATION}

J. L. Koole is a PhD candidate, M. J. L. Bours is an assistant professor, J. J. L. Breedveld-Peters is a scientist/dietitian, E. H. van Roekel is an assistant professor, and M. P. Weijenberg is a professor, Department of Epidemiology, GROW School for Oncology and Developmental Biology, Maastricht University, Maastricht, the Netherlands. M. C. J. M. van Dongen is an associate professor, Department of Epidemiology, CAPHRI Care and Public Health Research Institute, Maastricht University, Maastricht, the Netherlands. S. J. P. M. Eussen is an assistant professor, Department of Epidemiology, CARIM School for Cardiovascular Diseases, Maastricht University, Maastricht, the Netherlands. M. van Zutphen is a PhD candidate and F. J. B. van Duijnhoven is an assistant professor, Division of Human Nutrition and Health, Wageningen University \& Research, Wageningen, the Netherlands. H. C. Boshuizen is a professor, Division of Human Nutrition and Health, Wageningen University \& Research, Wageningen, the Netherlands, and the Department Statistics, Informatics and Mathematical Modelling, National Institute of Public Health and the Environment (RIVM), Bilthoven, the Netherlands.

Address correspondence to: Janna L. Koole, MSc, Department of Epidemiology, GROW School for Oncology and Developmental Biology, Maastricht University, PO Box 616, 6200 MD Maastricht, the Netherlands. E-mail: annaleen.koole@maastrichtuniversity.nl

\section{STATEMENT OF POTENTIAL CONFLICT OF INTEREST}

No potential conflict of interest was reported by the authors.

\section{FUNDING/SUPPORT}

This study and J. L. Koole were supported by a grant from Kankeronderzoekfonds Limburg as part of Health Foundation Limburg (Grant No. 00005739) and a grant from the Stichting Alpe d'HuZes within the research program "Leven met kanker" of the Dutch Cancer Society (Grant No. UM-2010-4867). E. H. van Roekel was financially supported by Wereld Kanker Onderzoek Fonds (WKOF), as part of the World Cancer Research Fund International grant programme (Grant No. 2016/1620).

\section{ACKNOWLEDGEMENTS}

We thank all participants of the EnCoRe study and the health professionals in the three hospitals involved in the recruitment of participants of the study: Maastricht University Medical Center+, VieCuri Medical Center, and Zuyderland Medical Center. We also thank the MEMIC center for data and information management for facilitating the logistic processes and data management of our study. Finally, we thank the research dietitians and research assistant who are responsible for patient inclusion and follow-up, performing home visits, as well as data collection and processing.

\section{AUTHOR CONTRIBUTIONS}

M. J. L. Bours and M. P. Weijenberg designed the study. J. L. Koole was involved in data collection and processing, performed the analyses, and wrote the original draft with contributions from M. J. L. Bours and M. P. Weijenberg. M. J. L. Bours, J. J. L. Breedveld-Peters, E. H. van Roekel, M. C. J. M. van Dongen, S. J. P. M. Eussen, M. van Zutphen, F. J. B. van Duijnhoven, H. C. Boshuizen, and M. P. Weijenberg reviewed and commented on subsequent drafts of the manuscript. 